\title{
A INTERAÇÃO ENTRE A FORMA E A MATÉRIA EM TOMÁS DE AQUINO E AS INTERAÇÕES DO SISTEMA CARTESIANO
}

\author{
Márcio Augusto Damin Custódio* \\ msdamin@unicamp.br
}

RESUMO Este artigo explora a relação que Descartes estabelece com as noções de forma e de matéria do aristotelismo escolástico ao tratar da interação entre as substâncias nas correspondências com Elisabeth, Gassendi e Arnauld. Partindo do exemplo do peso utilizado por Descartes em diversas cartas, traça-se uma relação de identidade entre a noção de forma em Tomás de Aquino e de pensamento em Descartes, assim como se traça a crítica à noção de forma, entendida como qualidade oculta, para os corpos inanimados. Por fim, explora-se a interpretação ocasionalista do sistema cartesiano e a relevância dos movimentos celestes para a explicação dos movimentos naturais em Tomás de Aquino.

Palavras-chave Cartesianismo, hilemorfismo, mecanicismo, causalidade, extensão.

ABSTRACT This paper deals with the relation that Descartes points between his system and concepts of matter and form from Aristotelian scholasticism. The resemblance arises when Descartes treats interaction among substances in correspondences with Elisabeth, Gassendi and Arnauld. Beginning with the example of the scholastic concept of weight, used many times by Descartes, this article traces an identity between concepts of form in 
Thomas Aquinas and of thought in Descartes, as well as traces his criticism on the concept of form, understood as hidden qualities, to inanimate bodies. Finally, this paper investigates Cartesian occasionalism as well as the importance of celestial movements for a better comprehension of nature in Thomas Aquinas.

Keywords Cartesianism, hylomorphism, mechanicism, causality, extension.

O tema da interação entre as substâncias no sistema cartesiano é motivo de debate entre Descartes e uma série de autores no século XVII, que argumentavam pela impossibilidade da alma causar movimento no corpo. Este é o caso de Elisabeth:

[...] como a alma do homem pode determinar os espíritos dos corpos para fazer as ações voluntárias, (nada mais sendo que uma substância pensante). Pois parece que toda determinação do movimento se faz pela impulsão da coisa movida, pela maneira que ela é impulsionada por aquilo que a move, ou melhor, pela qualificação e figura da superfície desse último. (Elisabeth para Descartes, 6/16 de maio de 1643; AT, III, 661)

A autora considera absurda a ideia de que algo desprovido de matéria, e, consequentemente, incapaz de impulso por contato, possa ser causa de qualquer movimento: "E eu advogo que me será mais fácil conceder a matéria e a extensão à alma, do que a capacidade de mover um corpo e de ser movido a um ser imaterial" (Elisabeth para Descartes, 10/20 de junho de 1643; AT, III, 685). Também Gassendi levanta a mesma dificuldade: "Como há contato sem corpo, quando (à luz natural é evidente [que]) tocar e não tocar não pode ocorrer sem corpo?" (AT, VII, 341).

Descartes, ao responder à Elizabeth, apresenta o exemplo do peso, que para os escolásticos é um princípio imaterial, inerente aos corpos, e que move um corpo para baixo assim como a alma move o corpo do homem. Ao fazêlo, Descartes não está defendendo nenhuma qualidade oculta do peso, o que considera erro já eliminado da física. ${ }^{1}$ A noção medieval de peso, mesmo

1 Vide o ataque contra a noção de qualidade dos escolásticos, na carta de Descartes a Morin, em 13 de julho de 1638 (AT, III, pp. 199-200). Vide também, sobre a exclusão nos corpos de tudo que não seja derivado da extensão, o ataque aos princípios vitais da fisiologia no "Traité de l'Homme" (AT, XI, p. 202). 
errada, parece ser para o autor um bom exemplo da facilidade com a qual se pode inteligir, sem necessidade de explicação ulterior, um princípio não material que causa movimento sem contato:

Por exemplo, supondo que o peso é uma qualidade real da qual nós não podemos ter outro conhecimento senão daquela força de mover os corpos para o centro da terra, nós não penamos para conceber como ela move esses corpos, nem como ela the é unida. E nós não concebemos que isso se faz por um contato real de uma superfície contra outra, pois experimentamos, em nós mesmos, que temos uma noção particular para concebê-la; e eu creio que usamos mal dessa noção ao aplicá-la ao peso, que nada é de realmente distinto dos corpos, como eu espero ter mostrado na Física, mas que nos foi dado para conceber o modo como a alma move o corpo. (Descartes a Elisabeth, 21 de maio de 1643; AT, III, 667-668)

Descartes sugere a Elisabeth que a interação entre a alma e o corpo opera de modo idêntico à relação entre a forma e a matéria na teoria do movimento dos escolásticos. ${ }^{2}$ Se, ao modo de Carriero (2009), entendermos Tomás de Aquino como parâmetro do aristotelismo escolástico referido por Descartes, podemos investigar o peso como um tipo de movimento e compreender como a forma opera, para Descartes, como princípio interno nos corpos naturais. ${ }^{3}$ Hattab (2009) fia-se neste tipo de abordagem do texto de Descartes, embora tenha se concentrado em compreender a alma como forma substancial, deixando pouco explorado o exemplo do peso da correspondência.

Neste artigo, mostro como a forma e a matéria, entendidos como princípio intrínseco do movimento, tal qual encontramos no aristotelismo de Tomás de Aquino, são apropriados por Descartes em seu exemplo do peso contra interpretações materialistas da interação entre substâncias no sistema cartesiano. ${ }^{4} \mathrm{O}$ exemplo, que analiso a partir das correspondências, é um dos poucos casos em que se encontra a relação entre o hilemorfismo e

2 Não se trata de analogia, mas de relação de identidade, uma vez que em ambos os casos há interações entre o pensamento ou forma e extensão ou matéria (Garber, 2001a, pp. 176-177).

3 Assumo, tal qual Carriero, que o aristotelismo tomista teve papel relevante na construção dos debates nos quais Descartes se envolveu. Embora Carriero formule sua hipótese pensando nas "Meditações", acredito que hipótese semelhante pode ser sustentada para os embates sobre a interação entre as substâncias presentes nas correspondências e debates com Elisabeth, Gassendi e Arnauld que trato aqui. Carriero expõe a hipótese na seguinte passagem: "Eu acredito, entretanto, que aspectos gerais do tomismo aristotélico auxiliaram a moldar os debates de Descartes e estabeleceram o cenário para boa parte de suas inovações filosóficas - muito mais do que outras formas de aristotelismo ou outras tradições de pensamento. Eu assumo (e isto não é controverso) que os professores jesuítas de Descartes em La Flèche deram-lhe uma boa impressão do aristotelismo tomista e (isto talvez seja mais controverso) que aquele treinamento deu-lhe algo que funcionou como um tipo de concepção padrão contra a qual desenvolveu sua própria filosofia, semelhantemente ao modo como seu próprio pensamento deu a Espinosa e a Locke um ponto de partida de suas próprias filosofias" (Carriero, 2009, p. 6).

4 Hattab acrescenta outro argumento aos de Carriero (2009). Para a autora, a noção de forma substancial contra a qual Descartes escreve tem origem em Tomás de Aquino (Hattabh, 2009, p. 31ss). 
o materialismo apontados diretamente pelo próprio autor. ${ }^{5}$ Por fim, mostro como o sistema cartesiano é muito mais dependente de Deus para explicar a causa da interação entre corpos que o sistema de Tomás de Aquino. ${ }^{6}$

Tomás de Aquino classifica o movimento segundo as diferentes categorias do ser ("In I Phys." lect. 1). Trata-se de uma classificação em vista do fim, uma vez que a forma só ocorre no sujeito do movimento, ou seja, na matéria, quando o movimento finda, dando origem a uma estrutura composta pelo substrato material e pela forma, sendo que tal composto não existia no princípio do movimento. ${ }^{7}$ Há o movimento do sujeito quanto à sua forma acidental e há mudança na categoria da substância. $\mathrm{O}$ movimento quanto à forma acidental ocorre nas três categorias que admitem contrários: a qualidade, na qual o movimento é denominado alteração, na quantidade, na qual é denominado aumento e diminuição, e na categoria do lugar, na qual é denominado locomoção ("In III Phys." lect. 1). O outro movimento, denominado mudança, ocorre na categoria da substância. ${ }^{8}$ Para realizar tal empreita, investigo a teoria do movimento de Tomás, com ênfase nas noções de forma e matéria, e termino tratando do movimento celeste, antes de retornar para uma breve consideração final sobre o ocasionalismo do sistema cartesiano.

Para Tomás de Aquino, o movimento entendido como o ato do que é em potência, com respeito ao que é em potência, ocorre entre dois términos, sendo um terminus ex quo, início do movimento, e outro terminus in quem, aquilo

5 Concordo com Hattab, para quem: "René Descartes dá poucos argumentos que apoiam diretamente sua rejeição das formas em favor dos mecanismos. Ademais, as poucas razões que oferece em seu corpus estão encriptadas e são difíceis de decifrar" (Hattab, 2009, p. 1).

6 Ao menos à luz de interpretações ocasionalistas, como a de Hatfield (1979) e Garber (2001a, b, c). Para uma concepção não ocasionalista da interação entre substâncias, vide: Westfall (1971) e Della Rocca (2002). Para minha posição sobre a questão, que procura compatibilizar a posição ocasionalista e uma certa quantidade de movimento na matéria, vide Custódio (2013).

7 Tomás de Aquino vincula-se fortemente a definição de natureza de Aristóteles como princípio do movimento e do repouso per se, não por acidente ("Phys." II, 1, 192b21-23). Tal princípio per se é forma, quando dito ativo, e matéria, quando dito passivo. A natureza, entendida como matéria, designa todas as possibilidades dos corpos de receberem determinações. Ademais, natureza como forma é princípio ativo de toda determinação da matéria (“In I De caelo", lect. 16, 13; "In III De caelo", lect. 7, p. 5-9). Há que se notar, entretanto, que a forma não é motor primeiro e por si dos corpos, uma vez que ela deve ser gerada, ou seja, vir a ser. Como afirma Weisheipl, "Quando a natureza, em sentido passivo, 'era movida' na geração de uma nova substância, era movida por outro: omine quod movetur ab alio movetur" (1965, p. 40). Desse modo, todo movimento de geração, uma das mudanças da categoria da substância, parece depender em alguma medida de um princípio externo. Porém, uma vez gerada, a substância move-se segundo sua forma e matéria, não necessitando de princípio externo algum.

8 Há, na verdade, duas mudanças, uma denominada geração e outra denominada corrupção, e não se deve compreendê-las como denominações dos contrários de uma mesma mudança, uma vez que não há contrários na categoria da substância. Tanto o movimento que diz respeito à forma acidental quanto a mudança da substância ocorrem em algo que permanece imóvel. Para que ocorra o movimento da forma acidental, o sujeito permanece imóvel; para a mudança na categoria da substância, o que permanece imutável é matéria ("In III Phys." lect. 1). 
em vista de quê o movimento ocorre, ou seu fim: "requer dois términos: um do qual o movimento tem início e outro para o qual o movimento procede, pois todo movimento é de algo para algo" ("In V Phys." lect 1, 641; vide "In V Meta." lect 11, 2361). Há que se notar que se exclui a possibilidade de que o próprio movimento seja fim, uma vez que aquilo que se move, move-se em vista de uma determinação que ainda não existe. Seria, então, contrassenso que o movimento fosse seu próprio fim ( $\mathrm{ScG} \mathrm{IV,} \mathrm{82),} \mathrm{assim} \mathrm{como} \mathrm{também}$ seria se os términos fossem móveis, de sorte que todo movimento principia e termina com a ausência de movimento:

Portanto, diz primeiro que aquilo que é movido primeiro e por si difere do término (in quem) para o qual tende o movimento e do término ( a quo) do qual o movimento teve início. Isto é evidente com respeito à madeira, ao calor e ao frio. Pois no movimento de calefação, a madeira é o móvel que difere do calor que é o término (ad quem) para o qual, e do frio que é o término (a quo) do qual. ("In V Phys." lect. 1, n. 5)

Os términos do movimento são contrários que se caracterizam pela eliminação recíproca, seja esta eliminação parcial ou integral. Em outras palavras, os términos são mutuamente excludentes, motivo pelo qual se diz que o movimento ocorre entre opostos ("In V Met." lect. 2). A oposição entre os términos é qualificada, tratando-se de contrapor o perfeito ao imperfeito, o ser ao não ser:

E diz que não apenas a geração é contrária a geração e a corrupção com respeito ao que é natural e antinatural, mas todos os movimentos e o repouso são contrários deste modo. Assim, o movimento para cima é contrário ao movimento para baixo (uma vez que o alto e o baixo são lugares contrários) e cada um desses movimentos é natural para algum corpo. Pois o fogo naturalmente sobe e a terra desce. Ademais, para cada um desses movimentos há diferentes contrários com respeito ao que é natural e antinatural. (“In I Phys.” lect. 10, n. 6)

Há, entretanto, razões para que se conceba um terceiro elemento entre os dois términos. Isto porque, uma vez que o princípio e o fim do movimento são contrários, não é o princípio do movimento que se transforma, aos poucos, no fim. Por exemplo, em um corpo quente que esfria, não é o calor, início do movimento, que esfria ou, do mesmo modo, não é o úmido que se torna seco. Deve-se acrescentar a isso que há identidade no que se move e continuidade no movimento entre um término e outro, de tal sorte que o sujeito do movimento permaneça o mesmo do princípio ao fim ("In I Phys." lect. 11 e 12).

Aporta-se, desse modo, a três termos do movimento, segundo Tomás: o sujeito que se move, a perfeição ou fim do movimento, e a privação ou 
início do movimento. ${ }^{9} \mathrm{O}$ sujeito do movimento, apto a transitar entre os dois términos, é a matéria. O fim do movimento, sua perfeição, é a forma por meio da qual o sujeito do movimento, a matéria, recebe uma determinação. O terceiro termo do movimento, a privação, não é distinto numericamente do sujeito ("In I Phys." lect. 15), a matéria, embora dela se diga "privação" para, com isso, indicar que não permanece no sujeito que se move, assim como se diz "matéria" daquilo que permanece ("In I Phys." lect. 12 e 13). Uma vez que a privação é numericamente idêntica ao sujeito há, na verdade, dois princípios do movimento, o próprio sujeito, substrato ou matéria, e a forma.

A esta divisão acrescenta-se outra, a divisão do ser em potência e em ato, sendo ela a responsável por mediar a passagem entre a privação e a recepção da forma ("In I Phys." lect. 9). O termo "ato" designa o princípio e o fim do movimento, sendo também chamado ato da forma ("In IX Met." lect. 3). O sujeito do movimento não é o ser em ato, uma vez que ainda não recepcionou a forma, nem é o não ser, exceto se se entende a expressão como indicando a privação da forma a ser recebida. Tal sujeito em movimento, o substrato material, é dito em potência para o ato. Ademais, uma vez que o ato é o fim do movimento e também o fim da potência, pode-se afirmar que o movimento é a transição da potência para o ato, restando denominá-la ato imperfeito. Cabe notar que se diz "imperfeito" porque o sujeito em movimento ainda não realizou o seu fim e, nesta media, é incompleto, uma vez que se relaciona a um ato futuro, o que indica sua privação ou potência:

Pois, quando a água é quente somente em potência, não há movimento. Quando está quente, o movimento de calefação terminou. Mas quando participa de algum modo do calor, embora imperfeitamente, está em movimento para o calor. Pois, aquilo que esquenta, paulatinamente participa do calor mais e mais. Pois o movimento é o ato imperfeito do calor, existindo na calefação não somente enquanto ato, mas na medida em que já existe em ato, possuindo uma ordenação para um ato ulterior. ("In III Phys." lect. 2, n. 3)

Pode-se investigar o movimento segundo a natureza, o que nos permite compreender o movimento na sucessão do tempo. Nesta investigação, partese da privação e move-se em direção à perfeição de uma determinação do ser. Há, porém, outra possibilidade, a de se investigar a perfeição segundo a natureza do sujeito que se move. Neste caso, dá-se anterioridade ao ato, uma vez que a perfeição já se encontra na natureza do sujeito, como seu melhor fim,

9 Como notou Elders (1975, 46-47), os términos do movimento são pensados tendo em vista um móvel que não possui a forma que irá adquirir. Nessa medida, o início do movimento caracteriza-se como uma privação da forma ("In I Phys." lect. 13). 
aquilo que lhe é desejável. Nesta investigação, prioriza-se a noção de desejo ou inclinação da matéria: "Dado que a forma é algum tipo de bem e desejável, e a matéria, que não é outra coisa senão a privação da forma, por sua natureza a procura e a deseja" (“In I Phys." lect 15, n. 8). O que é desejável à matéria é a forma, entendida como sua perfeição, ou término de seu movimento.

A noção de desejo ou inclinação aparece como elemento relevante do movimento para baixo promovido pela forma ou qualidade do peso de um dado corpo. É a noção de inclinação ou desejo que explica porque, para Descartes, não há uma simples relação de analogia entre a qualidade do peso, e seu movimento para baixo, e a alma, e sua capacidade de causar movimento no corpo. A relação a que Descartes se refere com o exemplo é de identidade, motivo pelo qual sempre retorna ao exemplo, como o faz para Arnauld cinco anos depois de tê-lo formulado para Elisabeth: "De sorte que nós não encontramos dificuldade para inteligir de que modo a alma move o corpo, quando eles [i.e., os escolásticos, compreendem] de que modo tal gravidade faz a pedra cair" (Descartes para Arnauld, 29 de julho de 1648; AT, $\mathrm{V}, 222-223)$. Tal qual Tomás concebia que o peso move um corpo para baixo, segundo sua inclinação ou desejo, assim também se deve compreender como a alma, que não é extensa, causa movimento no corpo segundo sua inclinação ou desejo.

Para Descartes, entretanto, inclinação ou desejo são noções derivadas do pensamento e não se pode, por exclusão, admiti-las na extensão, nem na natureza, exceção feita à união substancial do homem. Em vista dessa limitação, com seu exemplo Descartes informa a seus contemporâneos que os escolásticos aristotélicos erraram ao tentar explicar o movimento dos corpos naturais por meio da forma e da matéria. Informa, ainda, que o erro decorre de terem entendido o movimento humano como paradigma para tratar de todos os movimentos na natureza. Agindo desse modo, transformaram a alma humana em forma e a distribuíram para toda a natureza. Porém, com isso, viram-se obrigados a conceber que também os corpos naturais inanimados tem inclinações e desejos, como os corpos pesados teriam o desejo ou inclinação para baixo:

Porém, a evidência de que aquela ideia de gravidade foi decorrente principalmente de outra [ideia], a que eu tinha de alma, é que supus que a gravidade carregasse os corpos até o centro da terra, como se eles contivessem em si alguma cognição dele [i.e., do centro da terra]. Pois não poderia proceder deste modo sem que [alguma] cognição fosse feita, nem qualquer cognição pode ocorrer senão na alma. (AT, VII, 442) 
O exemplo de Descartes, deve-se acrescentar, não afeta somente a interação entre a alma e o corpo, mas principalmente a interação entre corpos. Isto ocorre porque, para os interlocutores de Descartes, o impacto não pode ser entendido como a causa da transferência de movimento entre corpos no sistema cartesiano, considerando que a extensão não guarda nenhuma qualidade ou força que possa transmitir. Com o exemplo dos corpos pesados, Descartes quer forçar seu interlocutor a concluir que a transferência de movimento, mesmo entre corpos, é causada por algo distinto da matéria, algo que não pode ser derivado da noção primitiva de extensão e que se assemelha a uma inclinação ou desejo, tal qual os escolásticos postularam existir entre os graves e seu lugar natural baixo. ${ }^{10}$

A solução, entretanto, aponta para a dificuldade de se inteligir a relação entre dois corpos. Uma vez que corpos são derivados da extensão, não pode ocorrer neles nenhuma ideia de inclinação ou vontade, tal qual a forma determinando a matéria, que seja a causa do movimento transmitido por contato. A ideia de contato, uma vez que também decorra exclusivamente da extensão, não pode ser tratada como idêntica à inclinação ou vontade que causa a transferência do movimento de um para outro corpo, e nada haveria nos corpos que pudesse ser inteligido como causa do movimento: a extensão é inerte, ou seja, isenta de formas. Aporta-se, desse modo, a uma dificuldade legítima de se explicar a interação entre corpos.

Para alguns cartesianos do século XVII, toda e qualquer interação entre corpos é causada não por contato, mas pelo intelecto divino, assim como o movimento do corpo de um homem é causado pelo seu intelecto. Esta é a solução de La Forge para a dificuldade:

Sustento que não há criatura, espiritual ou corpórea, que possa mudar a si ou qualquer de suas partes no segundo instante de sua criação se o criador não o fizer ele mesmo, uma vez que foi ele que fez esta parte da matéria no lugar A. Por exemplo, não apenas é necessário que ele continue a produzi-la se ele deseja que ela continue a existir, mas também, uma vez que ele não pode criá-la em todo lugar, nem pode criá-la sem lugar, ele deve por si colocá-la no lugar B, se ele a quer ali, pois se ele a quisesse colocar em algum outro lugar, não haveria força capaz de removê-la de lá. (La Forge, 1974, 240)

10 Interessa-me o contexto da correspondência com Elisabeth, na qual Descartes apresenta sua teoria das noções primitivas: "Primeiramente, eu considero que há em nós certas noções primitivas que são como que originais, sobre o padrão das quais nós formamos todos os nossos outros conhecimentos. E não há nada mais forte do que tais noções. Assim, depois das mais gerais, do ser, do nome, da duração, etc., que convém a tudo que nós podemos conhecer, nós temos, para os corpos em particular, a noção de extensão, da qual se seguem aquelas da figura e do movimento; e exclusivamente para a alma nós temos aquela do pensamento, da qual se compreende as percepções do entendimento e as inclinações da vontade" (Descartes para Elisabeth, 21 de maio de 1643; AT, III, 665, grifo meu). 
A interpretação de La Forge não é incompatível com algumas passagens de Descartes, ao contrário, como se pode perceber na seguinte carta:

Por outro lado, a força movente pode ser o próprio Deus, conservando o mesmo tanto de translação na matéria que ela possuía no momento primeiro da criação; ou pode ser a substância criada, que é a nossa alma, ou qualquer outra coisa para a qual ele deu a força para mover um corpo. (Descartes a More, agosto de 1649; AT, V, 403404)

Esta concepção, ocasionalista, tem por propósito preservar a matéria geometricamente descrita e livre de qualquer princípio ou força, idêntico à forma do aristotelismo de Tomás de Aquino e que não possam ser derivados da noção primitiva de extensão. Momento a momento, o Deus de Descartes move, atribuindo a um corpo o movimento que se encontrava em outro corpo, de tal sorte que a quantidade total de movimento na natureza permaneça a mesma. A cada momento que Deus move os corpos, cria o mundo, uma vez que não há ação de Deus que não seja criação.

Se se admitir esta interpretação ocasionalista, o preço explicativo pago por Descartes ou, ao menos, por cartesianos como La Forge para eliminar da natureza as qualidades ocultas parece, à primeira vista, alto demais. É, certamente, um preço que Tomás de Aquino não precisa pagar ao sustentar, com seu sistema hilemórfico, um princípio intrínseco aos corpos naturais como causa de seu movimento natural. A que se notar que tanto para Tomás quanto para Descartes a matéria é passiva. Porém, a causa efetiva em Tomás é parte da estrutura de cada corpo natural que se move segundo suas determinações naturais. Como as determinações são distintas para cada espécie, não há um conjunto de leis gerais do movimento, mas a totalidade de espécies criadas.

O preço pago por Descartes, embora alto quanto à causalidade, permite que ele abandone as determinações segundo a espécie e adote um conjunto unificado de leis do movimento. O que das leis da natureza se intelige é que Deus age para preservar a mesma quantidade de movimento no mundo, desde o primeiro momento da criação. A preservação do movimento, por seu turno, deriva da própria imutabilidade de Deus, e esta deriva de sua perfeição. Deus age no mundo, portanto, segundo o princípio da conservação, mas o faz especialmente quando um corpo colide com outro.

Segue-se que é maximamente consistente com a razão, que acreditamos com base somente nisto, que Deus moveu as partes da matéria de diferentes modos quando primeiro as criou, e que agora conserva toda a matéria do mesmo modo pela mesma razão que ele a criou antes, que ele conserva a mesma quantidade de movimento nela sempre. (AT, VIII, 62) 
Evidentemente, também se pode dizer com correção, em Tomás de Aquino, que Deus é a causa do movimento. Porém, ele não o é como causa eficiente dos movimentos naturais dos corpos compostos de matéria e forma. Em Tomás, Deus não atua momento a momento para conservar o movimento dos corpos naturais. O movimento é causado segundo a forma, uma vez que é por meio dela que o substrato recebe a determinação. Contudo, uma vez que é na matéria que ocorre o movimento, a causa motora não é delimitada apenas pela forma, mas também pela condição passiva da matéria de receber a ação ("In III Phys." lect. 5, 314). Afinal, o movimento produzido pela forma não pode ser contrário à disposição material de recebê-la. Não sendo contrário, diz-se do movimento que é natural, necessário; sendo contrário à disposição material, diz-se que o movimento é antinatural e ocorre por violência. ${ }^{11}$

Para todo movimento natural há uma dupla relação entre o motor e o móvel, uma vez que se pode dizer de ambos na categoria da quantidade e nas categorias da passividade e da ação, sendo estas duas últimas as que tratam do princípio ou fim do movimento ("In III Phys." lect. 5, 314). Tem-se, assim, a combinação das quatro causas. A eficiente conecta o motor ao móvel e está garantida pela internalização do princípio formal do movimento. Este, no que concerne à atividade, é causado pela forma e, no que concerne à passividade, é recebido pelo substrato, causa material do movimento. Como todo movimento é em vista de um fim, de um terminus in quem que é a determinação pela recepção da forma, as causas formal e material resolvem-se na causa final por diferentes modos. A causa formal doando a ação e a causa material recebendo a ação. Acrescente-se, como já dito, que o ato é anterior a potência, de sorte que, aquilo que é resultado do movimento, de algum modo preexiste, não numericamente, mas em espécie. Enquanto tal, permanece estável, perfeito, para além das contingências do mundo natural.

A participação no que permanece estável, perfeito, para além do mundo natural não pode residir nos compostos de matéria e forma do mundo sublunar, uma vez que não estão isentos de movimento e mudança. ${ }^{12}$ Faz-se, assim, necessário o mundo estável no qual não existe contrários, nem geração ou corrupção. Tomás, seguindo Aristóteles ("In II De caelo", lect. 1), assume

11 "Portanto, diz que aquilo que ocorre por violência é antinatural. (Pois o violento é aquilo cujo princípio é extrínseco, e a violência não contribui com nada. O princípio natural, entretanto, é interno)" ("In V Phys." lect. 10, n. 4).

12 Clarke argumenta que não se pode ignorar a influência do platonismo, quando Tomás altera a teoria do ato e da potência para incluir uma concepção de participação dos corpos corruptíveis e mutáveis nas essências imutáveis e incorruptíveis (Clarke, 1952, 190-193). Contra a concepção de Clarke de que há adesão ao neoplatonismo, vide Cantens (2000). 
a divisão do mundo em duas partes distintas, a terrestre ou sublunar, e a celeste ou supralunar. A parte sublunar é passível de geração e corrupção, bem como dos demais movimentos das categorias acidentais da quantidade, da qualidade e do lugar. No mundo sublunar, corpos compostos de matéria e forma transformam-se o tempo todo. Na parte celeste ou supralunar não há quatro elementos, mas apenas um quinto, que não é passível nem de geração, nem de corrupção, e que se move tão somente com movimento local, circular e uniforme ao redor do centro geométrico do mundo. ${ }^{13}$

Poderia haver dúvida quanto a perfeição dos corpos celestes precisamente por conta de moverem-se com movimento circular, ferindo, desse modo, a relação direta que há entre perfeição e imobilidade. Entretanto, Tomás de Aquino sustenta que o movimento local, por meio do qual os corpos celestes realizam seu movimento circular, é o que menos indica imperfeição. Isto porque, o que se move com movimento local sofre apenas movimento externo, ao passo que todos os outros movimentos indicam alterações intrínsecas ao móvel (ScG III, 82). Ademais, os corpos celestes estão mais próximos da imobilidade e, consequentemente, mais próximos da perfeição, uma vez que não passam por mudança em sua substância, segundo a geração e a corrupção, nem em sua qualidade, por alteração. Pode-se, ainda, argumentar que Tomás segue muito próximo o texto do "De caelo", ao entender que a imobilidade da qual Aristóteles trata diz respeito a passagem entre contrários. Movimentos locais simples podem ter apenas um contrário, como é o caso dos corpos da região sublunar, movendo-se para o alto ou para o baixo. Na região supralunar, entretanto, só há ocorrência de movimento simples circular, que carece de contrários. $^{14}$

Ainda assim, os corpos celestes, uma vez que se movem com movimento circular local, são movidos por outro, ${ }^{15}$ e como o regresso não pode continuar

13 Tomás segue, em grande medida, o sistema de esferas concêntricas em movimento proposto por Aristóteles (Dicks, 1970, pp. 200-201). Este é o caso da referência que Tomás faz à "Metafísica" XII em seu comentário ("In II De caelo", lect. 17 e 19). Não entro em detalhes sobre o movimento dos céus, como, por exemplo, a distinção entre os corpos celestes e seus motores. Devo ressaltar, entretanto, que para Tomás o problema dos motores celestes não é teológico, mas parte da ciência especulativa; mais especificamente, da astronomia física (Weisheipl, 1961, p. 299).

14 Não há contrário no movimento circular que ocorre em uma mesma circunferência, porém em direção oposta. Isto porque, no caso do movimento na categoria do lugar, os contrários são os términos do movimento, sendo um a privação da determinação do outro. Um móvel que complete toda a circunferência alcançará, ao final do movimento, o mesmo lugar do início, e não um término final e contrário ao término inicial ("In II De caelo", lect. 13).

15 Os corpos celestes não podem ser tratados como os corpos naturais que, como vimos, possuem um princípio interno de movimento, a saber, a forma quanto ao que é ativo e a matéria quanto ao que é passivo. A razão para não poderem ter um princípio formal de movimento é o fato de não se moverem para uma determinação, a partir da ausência dessa determinação, uma vez que tal movimento seria finito, com dois términos, um início e um fim. A solução, para evitar a admissão de términos para o movimento 
ao infinito, faz-se necessário um primeiro motor imóvel, este sim, permanente, imutável, perfeito (ScG I, 13). Contudo, há que se esclarecer como tal motor pode mover sem ser movido, uma vez que, como vimos, ao menos na natureza, o ato precede a potência e todo princípio de movimento parece ser intrínseco. Evidentemente, a pergunta pelo motor imóvel do movimento não instaura uma causa efetiva, externa aos corpos naturais. Sejam os motores das esferas celestes, seja o primeiro motor, nenhum deles funciona como causa eficiente dos corpos naturais, mas como causa final, uma vez que causam movimento por serem desejados (O'Connor, 1948).

Pode parecer estranho que todos os entes celestes, ao desejarem a imobilidade, façam exatamente o contrário, ou seja, movam-se. Contudo, o que desejam, o que a imobilidade exprime, é a perfeição e a permanência. $\mathrm{O}$ desejo de perfeição se realiza duplamente: no âmbito natural pela inclinação que a matéria tem para receber a forma, mas também na garantia de que há estabilidade e perfeição em um primeiro motor que é o início de todo movimento. Há, desse modo, uma redução do movimento à perfeição, entendida como a imobilidade do primeiro motor. A imobilidade garante que o primeiro motor seja perfeito, na medida em que nenhum movimento pode levá-lo à corrupção, a perda de seu ser em ato (Kretzmann, 1966, 409, n. 1). Ademais, o ser imóvel é puro ato, não possuindo nenhuma privação que possa se caracterizar como início do movimento (ST I, q. 9, a. 1). Emerge, desse modo, outro princípio motor, porém um que não se encontra no domínio da física, da natureza:

E não apenas o primeiro motor e o primeiro sujeito são considerados quanto a geração, mas também todos os que lhe são consequentes. E, assim, é evidente que pertence à filosofia natural considerar a forma, o móvel e a matéria. Pois há dois tipos de princípios motores, o que se move e o imóvel. Um motor que não é móvel não é natural, pois não tem em si o princípio do movimento. E tal é o princípio motor que é ao mesmo tempo imóvel e primeiro para todos os móveis, como será exposto no Livro VIII. ("In II Phys.” lect 13, n. 5)

A resolução do movimento na imobilidade pode ser assim descrita (Aertsen, 1988, 138): primeiro, o movimento é reduzido ao princípio natural, interno aos entes naturais, a matéria e a forma, que se relacionam tal como a potência e o ato. Na sequência, o movimento é reduzido a causas externas aos entes naturais, a saber, o princípio ativo, agente e fim. O fim, é governado pela 
permanência ou eternidade, o que requer uma ordenação ou hierarquia dos móveis segundo sua menor mobilidade. Tal ordem reserva aos corpos celestes o lugar no mundo de maior importância, uma vez que são tais corpos os que possuem menor mobilidade, considerando que não mudam substancialmente nem se alteram qualitativamente. Por fim, o movimento é reduzido ao primeiro motor imóvel.

Há coerência entre o início do processo de redução do movimento, quando se fala dele no domínio da natureza, e a conclusão do processo, quando se trata do movimento no domínio da perfeição do primeiro motor. No domínio da natureza, o movimento é entendido a partir da matéria e da forma e, dada a garantia de redução ao primeiro princípio imóvel, tem-se que a resolução natural, em cada ser, de seu movimento natural, é garantia de perfeição, término do movimento segundo a essência. Há que se notar que o movimento não termina com a transmutação do ser que se move, mas com sua perfeição. $\mathrm{O}$ ser, ao término do movimento permanece o mesmo, porém recebe uma determinação que não lhe era efetiva no início do movimento.

A cosmologia de Tomás de Aquino parece, à primeira vista, introduzir complexidade desnecessária à explicação da causa do movimento. Porém, há que se considerar que a natureza, o mundo sublunar, pode, em Tomás, ter seu movimento investigado em separado do céu, mundo supralunar, e do primeiro motor imóvel. A investigação requer um único princípio interno aos corpos compostos para explicar a causa dos movimentos de quantidade, qualidade e lugar, bem como da mudança na categoria da substância, sob certo aspecto. Para tanto, Tomás mobiliza as noções de matéria e forma, potência e ato, e inclinação ou desejo natural. Descartes, ao apresentar o exemplo do peso a seus contemporâneos, crê encontrar identidade entre o princípio interno de movimento, tal qual encontramos em Tomás, e o pensamento como causa dos movimentos dos corpos. Ao eliminar a forma dos corpos materiais, entretanto, Descartes vê-se obrigado a constituir um Deus interventor que, a cada momento, causa os movimentos naturais, segundo leis de conservação de sua criação. O grande ganho explicativo de Descartes assenta-se, precisamente, no pequeno conjunto de leis naturais que substitui a plêiade de essências e suas respectivas determinações, em vista das quais, para Tomás e para o aristotelismo escolástico, cada movimento era causado. Elisabeth, Gassendi e Arnauld, entretanto, parecem reticentes em abandonar a ideia de que deve haver algo na matéria que, por contato, transfere movimento de um corpo para outro. 


\section{Referências}

ADAN, C; TANNERY, P. “Oeuvres de Descartes”. Paris: J. Vrin, 1996. AQUINO, T. "Commentaria in octo libros Physicorum Aristotelis". Roma: Leoninas. Tomo II, 1884.

AQUINO, T. "De Aeternitate Mundi”. Ed. H. F. Dondaine. Roma: Leoninas. Tomo XLIII, Opuscula, Vol. IV, 1976.

AQUINO, T. "Expositio in duodecim libros Metaphysicorum Aristotelis". Roma: Marietti, 1950.

AQUINO, T. "In libros Aristotelis De caelo et mundo expositio". Roma: Leoninas. Tomo III, 1886.

AQUINO, T. "Quaestiones disputatae de Potentia Dei”. Ed. P. Mandonnet. Tomo II, Paris: P. Lethielleux, 1925.

AQUINO, T. "Scriptum Super Libros Sententiarum Magistri Petri Lombardi”. Ed. P. Mandonnet. Paris: P. Lethielleux, 1929.

AQUINO, T. "Summa contra gentiles". Roma: Marietti, 1961-1967.

AERTSEN, J. "Nature and Creature". Leiden: E. J. Brill, 1988.

BALDNER, E. S. Thomas Aquinas on Celestial Matter. "The Thomist", 68, 2004. pp. 431-467.

BEYSSADE, J-M. "La philosophie première de Descartes". Paris: Flammarion, 1979. CANTENS, B. "The Interdependency between Aquinas's Doctrine of Creation and his Metaphysical Principle of the Limitation of Act by Potency". Proceedings of the American Catholic Philosophical Association, Vol. 74, pp. 121-139, 2000.

CARRIERO, J. "Between Two Worlds: A Reading of Descartes's Meditations". Princeton University Press, 2009.

CLAGETT, M. "Science of Mechanics in the Middle Ages". Madison: University of Wisconsin Press, 1959.

CLARKE, N. "The Limitation of Act by Potency: Aristotelianism or Neoplatonism". The New Scholasticism, 26, pp. 167-194, 1952.

COHEN, B. "'Quantum in se est': Newton's Concept of Inertia in Relation to Descartes and Lucretius". Notes and Records of the Royal Society of London, Vol. 19, Nr. 2, pp. 131-155, 1964.

CURLEY, E. "Descartes on the Creation of the Eternal Truths". The Philosophical Review. Vol. 93, Nr. 4, pp. 569-597, 1984.

CUSTÓDIO, M. A. D. "Causa e transferência de movimento nas interações do sistema cartesiano". Ideação, Vol. 1, Nr. 28, pp. 13-45, 2013.

DELLA ROCCA, M. "If a Body Meet a Body; A Descartes Body-Body Causation". In: R. J. GENNARO; C. HUENEMANN, 2002. pp. 48-81.

DICKS, D. "Early Greek Astronomy". Cornell: Cornell University Press, 1970.

DIJKSTERHUIS, E. J. "The Mechanization of the World Picture”. Oxford: Claredon Press, 1961.

DUHEM, P. “Le système du monde”. Vol. 1. Paris: Hermann, 1913. 
ELDERS, L. J. "St Thomas Aquinas's Commentary on Aristotle's Physics". Review of Metaphysics, Vol. 66, Nr. 4, pp. 713-748, 2013.

ELDERS, L. "La philosophie de la nature de Saint Thomas d'Aquin; Philosophie générale de la nature cosmologie; Philosophie du vivant; Anthropologie philosophique". Paris: Pierre Téqui, 1994.

ÉVORA, F. R. R. "De quelle façon le Premier Moteur non-susceptible de mouvement gouverne-t-il le mouvement éternel des corps célestes?”. In: F. R. R. Évora; M. A. D. Custódio (org.), 2010. pp. 09-27.

ÉVORA, F. R. R.; CUSTÓDIO, M. A. D. (org.). "Matter/Extension and Movement". Coleção de Estudos de História da Filosofia da Natureza, Vol. 1. Campinas: IFCHUNICAMP, 2010.

FRANKFURT, H. "Descartes on the Creation of the Eternal Truths". The Philosophical Review, Vol. 86, Nr. 1, pp. 569-597, 1977.

FREDDOSO, F. "Medieval Aristotelianism and the Case Agaisnt Secondary Causation in Nature". In: T. Morris (ed.), 1988. pp. 74-118.

GABBEY, A. "Force and Inertia in the Seventeenth Century: Descartes and Newton". In: S. Gaukroger (ed.), 1980. pp. 230-320.

GARBER, D. "Understanding Interaction; What Descartes Should Have Told Elisabeth". In: Descartes Embodied. Cambridge: Cambridge University Press, 2001a. pp. 168-188.

GARBER, D. “Descartes and Occasionalism”. In: Descartes Embodied. Cambridge: Cambridge University Press, 2001b. pp. 203-220.

GARBER, D. "How God Causes Motion". In: Descartes Embodied. Cambridge: Cambridge University Press, 2001c. pp. 189-202.

GAUKROGER, S. (ed.). "Descartes: Philosophy, Mathematics and Physics". Sussex: Harvester Press, 1980.

GENNARO, R. J; HUENEMANN, C. "New Essays on the Rationalists". Oxford: Oxford Scholarhip Online, 2002.

GRANT, E. "'Celestial Motions in the Late Middle Ages". Early Science and Medicine, 2, 2, pp. 129-148, 1997.

GUEROULT, M. "The Metaphysics and Physics of Forces in Descartes". In: S. Gaukroger (ed.), 1980. pp. 196-229.

HATFIELD, G. "Force. (God) in Descartes P." Studies in History of Philosophy of Science, Vol. 10, Nr. 2, pp. 113-140, 1979.

HOENEN, P. “Descartes' Mechanicism”. In: D. Willis (ed.), 1967. pp. 353-368. HATTAB, H. "Descartes on Forms and Mechanisms". Cambridge: Cambridge University Press, 2009.

KOYRÉ, A. "Études newtoniennes". Paris: Gallimard, 1968.

KRETZMANN, N. "Omniscience and Immutability". The Journal of Philosophy, Vol. 63, Nr. 14, pp. 409-421, 1966. 
KRETZMANN, N.; KENNY, A.; PINBORG, J.; STUMP, E. "Cambridge History of Later Medieval Philosophy: From Rediscovery to the Disintegration of Scholasticism". pp. 1100-1600. Cambridge: Cambridge University Press, 1982.

LA FORGE, L. “Traité de l'esprit de l'homme". In: Oeuvres philosophiques. Paris: Presses Universitaires de France, 1974.

MAIER, A. "Die Vorläufer Galileis im 14. Jahrhundert". Roma: Edizioni di Storia e Letteratura, 1949.

MARÉCHAL, J. "Le point de départ de la métaphysique". Cahier V. Louvin, 1926. MORRIS, T. (ed.). "Divine and Human Action: Essays in the Metaphysics of Theism". Ithaca: Cornell University Press, 1988.

NADLER, S. "Descartes and Occasional Causation". British Journal for the History of Philosophy. Nr. 2, pp. 35-54, 1994.

O'CONNOR, W. "The Natural Desire for God". Aquinas Lecture, 13. Milwaukee: Marquette University Press, 1948.

O'MAHONY, J. "The Desire of God in the Philosophy of St. Thomas Aquinas". Cork University Press, 1929.

PLANTINGA, A. "Does God have a Nature?" Milwaukee: Marquette University Press, 1980.

PRENDERGAST, T. L. "Motion, Action, and Tendency in Descartes' Physics". Journal of the History of Philosophy, Vol. 13, Nr. 4, pp. 453-462, 1975.

ROBERTS, L. D. "Approaches to Nature in the Middle Ages". Papers of the Tenth Annual Conference of the Center for Medieval and Early Renaissance Studies. Binghamton: Center for Medieval and Early Renaissance Studies, 1982.

STORK, A. "Deus autem et natura nihil frustra faciunt. Notas sobre a teleologia nos comentários de Tomás de Aquino a Aristóteles". Cadernos de História e Filosofia da Ciência, S. 3, Vol. 16, Nr. 1, pp. 59-63, 2006.

WELLS, N. J. “Descartes Uncreated Eternal Truths”. New Scholasticism, 56, pp. 185199, 1982.

WESTFALL, R. "Force in Newton's Physics; The Science of Dynamics in Seventeenth Century". New York: Elsevier, 1971.

WALLACE, W. "Causes and Forces in Sixteenth-century Physics". Isis, Vol. 69, Nr. 3, pp. 400-412, 1978.

WALLACE, W. "On the Temporal Relation between Cause and Effect". The Review of Methaphysics, Vol. 27, Nr. 3, pp. 569-584, 1974.

WEISHEIPL, J. A. "The Principle omne quod movetur ab alio movetur in Medieval Physics”. Isis, Vol. 1, Nr. 56, pp. 26-45, 1965.

WEISHEIPL, J. A. "The Celestial Movers in Medieval Physics". Thomist, a Speculative Quarterly Review, 24, 2/4, pp. 286-326, 1961.

WEISHEIPL, J. A. "The Commentary of St. Thomas Aquinas on the De Caelo of Aristotle”. Sapientia, XXIX, pp. 11-34, 1974.

WEISHEIPL, J. A. "The interpretation of Aristotle's Physics and the Science of Motion”. In: N. Kretzmann, A. Kenny, J. Pinborg, E. Stump, 1982. pp. 521-536. 
WEISHEIPL, J. A. “Aristotle's Concept of Nature: Avicena and Aquinas”. In: L. D. Roberts, 1982b. pp. 137-160.

WILLIS DONEY (ed.). "Descartes: A Collection of Critical Essays". Garden City: Doubleday, 1967. pp. 353-368. 